\title{
Contribution of cancer leagues to the promotion and organisation of cancer screening programmes
}

David Ritchie

Association of European Cancer Leagues, Brussels, Belgium

\begin{abstract}
The European Union Council Recommendation of 2003 outlines the key principles of best practice in the systematic screening and early detection of cancer, calling on EU member states to develop and implement organised, population-based screening programmes for breast, cervical and colorectal cancer. This short communication outlines, with three practical examples, the variety of ways in which cancer leagues are supporting the development, management, and quality improvement of organised cancer screening in the wider European region.

The contribution of cancer leagues is a key sustaining factor for the full and equitable implementation of organised cancer screening programmes, in compliance with the EU guidelines for quality assurance in cancer screening. Both the Portuguese League against Cancer and the Icelandic Cancer Society manage and implement the national breast cancer programmes in their respective countries. The Icelandic Cancer Society also manages the cervical cancer screening programme in parallel. The Israel Cancer Association initiated, and funded for over two decades, the national mammography screening programme in Israel, which has been instrumental in eliminating the disparity in screening participation between Jewish and Arab ethnic women.

As initiators, programme managers, and disseminators of information to professionals and the target groups for screening, cancer leagues perform essential and diverse roles supporting cancer screening programmes to achieve their goals. ECL intends to harness this activity in the coming years by deepening the collaboration between cancer leagues on this issue, thereby acting on the ECL's strategic goal to "encourage access to cancer screening."
\end{abstract}

KEY WORDS: cancer prevention, cancer screening, civil society, health communication, early detection of cancer, Europe, socio-economic inequalities.

ADDRESS FOR CORRESPONDENCE: David Ritchie, Association of European Cancer Leagues, Chaussée de Louvain 479, 1030 Brussels, Belgium, e-mail: david@europeancancerleagues.org

\section{INTRODUCTION}

The European Union (EU) Council Recommendation of 2003 outlines the key principles of best practice in the systematic screening and early detection of cancer, calling on EU member states to develop and implement organised, population-based screening programmes for breast, cervical and colorectal cancer [1]. It covers factors such as the registering and managing of screening data, monitoring the screening process, and the training of implicated personnel.

Organised screening programmes are recommended as they are best placed to put the European guidelines for quality assurance in screening into practice to achieve the greatest benefit with the least harm [2]. Members of the public are encouraged to attend screening following an invitation from the organised programme and after having considered the potential benefits and risks of screening in respect of their personal values and preferences [3]. This recommendation has since been reinforced by the $4^{\text {th }}$ edition of the European Code against Cancer [4].

The Association of European Cancer Leagues (ECL) provides a unique platform in Europe as the only organisation with the mission of uniting, at the European level, national and regional cancer leagues to achieve a can- 
cer-free Europe. Active since 1980, ECL counts 26 members from 23 countries in the WHO European Region, encompassing $19 \mathrm{EU}$ member states. To guide the work of ECL, a multi-annual strategy is in place (covering 2014-2018), and is composed of 5 strategic goals, the $3^{\text {rd }}$ of which is to "encourage access to cancer screening" [5].

Financed mainly by the generosity of European citizens, cancer leagues work across the entire spectrum of cancer control, from fundamental research through to providing rehabilitation and palliative care. In regards to cancer screening, cancer leagues adopt a variety of roles in the development, management, and promotion of organised cancer screening. This short communication will elaborate, with concise examples, the various functions cancer leagues perform in respect of organised cancer screening programmes.

\section{CANCER LEAGUES CONTRIBUTION TO ORGANISED CANCER SCREENING PROGRAMMES}

Published in 2017, the second implementation report of cancer screening programmes in the European Union [2] demonstrates the considerable progress that has been made in recent years, but indicates that substantial variation in screening coverage remains. The report found that, as of 2016, $25 \mathrm{EU}$ member states were planning, piloting, or rolling out population-based breast cancer screening programmes; $22 \mathrm{EU}$ member states were doing likewise for cervical cancer screening, and $23 \mathrm{EU}$ member states were in preparation or implementing colorectal cancer screening programmes.

Despite the widespread roll-out and increasing coverage of these programmes, socio-economic inequalities in the mortality rates of those cancers recommended for organised screening are still found in many countries [6]. For example, in Poland, mortality rates in women with a lower education level are substantially higher than mortality rates in women with lower economic status. In young women, cervical cancer is approximately 10 times higher among less educated women compared to those with higher education. In addition, women of lower socio-economic status are characterised by lower participation rates in cervical cancer screening [7]. Implementing organised cancer screening programmes following quality assurance guidelines can, therefore, address this inequality by detecting cancers (or pre-cancerous lesions) at an early, and therefore, more treatable stage. This in turn leads to reduced cancer mortality rates [8].

Cancer leagues in Europe perform many essential functions in cancer screening, ranging from the management and delivery of cancer screening services, to the promotion of screening to target groups, taking full account of socio-economic inequalities, and the provision of support for cancer registry data for the monitoring and evaluation of cancer screening programmes.
The following examples provide a snapshot of the variety of roles that cancer leagues provide.

\section{PORTUGUESE LEAGUE AGAINST CANCER: MANAGEMENT AND IMPLEMENTATION OF POPULATION-BASED BREAST CANCER SCREENING PROGRAMME}

The Portuguese League against Cancer (LPCC) is a non-profit, non-governmental organisation, founded in 1941, headquartered in Lisbon. The activities of the LPCC are developed and implemented through 5 regional branches: North, Centre, South, Madeira, and the Azores.

The objectives of the LPCC include: to disseminate information on cancer and promote health education; contribute to the social support and care for cancer patients; and provide support for oncology training and research. In addition, LPCC is mandated by the Portuguese national authorities to manage and implement the national breast cancer screening programme.

Following the pilot action (1986-1990) managed by LPCC, the organised population-based breast cancer screening programme was initiated in 1990. This activity involved 18 counties from the Central Region of Portugal. The "European against Cancer" programme supported the subsequent roll-out of the breast cancer screening programme, which was accompanied by similar actions in Dublin, Navarra, Flanders, Strasbourg, Athens, and Florence [9].

In 2000, the LPCC created a 'National Breast Cancer Screening Programme', which combined the three existing regional programmes into one national coordination office, adopting comparable quality control, monitoring, and information system mechanisms. To facilitate this integration, a bespoke Management Information System (MIS) was designed and developed by the LPCC.

Table 1 outlines certain key information about the breast cancer screening programme in Portugal. In total, more than 3 million mammography tests have been performed in the past 25 years, 130,000 women have been assessed, and more than 15,000 women referred to hospital for final diagnosis and treatment.

The results of a recently published case-referent study by the LPCC indicate that the breast cancer screening programme in Portugal contributes towards decreasing breast cancer mortality in Portugal. Such information should be used to support invited women to make an informed-decision about whether or not to attend screening [10].

\section{ICELANDIC CANCER SOCIETY: MANAGEMENT AND IMPLEMENTATION OF POPULATION- BASED BREAST AND CERVICAL CANCER SCREENING PROGRAMMES}

The Icelandic Cancer Society (ICS) is an umbrella organisation of 29-member associations, local associ- 
TABLE 1. Selected information on the Portuguese Breast Cancer Screening programme

\begin{tabular}{|c|c|}
\hline Description & Data \\
\hline Age range & $\begin{array}{l}\text { Algarve: } 50-69 \\
\text { years } \\
\text { Azores: } 45-74 \text { years } \\
\text { All other regions: } \\
45-69 \text { years }\end{array}$ \\
\hline Screening interval & 2 years \\
\hline Participation rate & $63 \%$ \\
\hline $\begin{array}{l}\text { Invitation coverage (on annual } \\
\text { population) }\end{array}$ & $55 \%$ \\
\hline $\begin{array}{l}\text { Is written information on benefits } \\
\text { and harms of screening provided? }\end{array}$ & Yes \\
\hline
\end{tabular}

ations, and support groups, which was established in 1951. Since its establishment, ICS has concentrated its efforts on cancer prevention, education, research, and patient support. ICS also supports the National Cancer Registry, established in 1954 thus making it one of the oldest nationwide cancer registries in the world.

Screening for cervical cancer and breast cancer is one of the most extensive tasks of the Cancer Society. Since 1964, the Cancer Detection Clinic of the ICS has managed the cervical cancer screening programme, and screening for breast cancer from 1987. The service provided by ICS is organised and managed in cooperation with the Icelandic Directorate of Health and Icelandic National Health Insurance. For cost-effectiveness, the mammography screening is organised jointly with cervical cancer screening.

Table 2 provides brief information on the cervical cancer screening programme in Iceland. Cervical cancer screening is available every three years for women aged 23 to 65 years old. In the case of breast cancer screening, women aged 40 to 70 years old are invited every two years. Screening takes place at the ICS service centre in Reykjavík, at most primary care clinics outside the capital area, and at the Akureyri hospital radiology ward [11]. Women resident in Iceland with no cervical cytology, HPV test or histology in the last 3 years are personally invited without scheduled appointments. Women with a previous cervical or uterine cancer diagnosis are excluded, as are women who have opted out from receiving letters from the programme. Invitations to women are provided as traditional, mailed letters, with an open reminder used on an annual basis.

For breast cancer screening, Table 3 provides brief information on the Icelandic programme. All mammograms in Iceland are read at the Cancer Detection Clinic (CDC) in Reykjavik. Women with an abnormal screening mammography are recalled for further workup with additional views, ultrasound examination, and needle biopsies (fine needle or core biopsies) before deciding whether to
TABLE 2. Selected information on the Icelandic Cervical Cancer Screening programme

\begin{tabular}{|l|l|}
\hline Description & Data \\
\hline Primary screening test & Cytology \\
\hline Interval between negative screens & 3 years \\
\hline $\begin{array}{l}\text { Total population in the national target age } \\
\text { range (age: } 23-65)\end{array}$ & 93,640 \\
\hline $\begin{array}{l}\text { Total number of tests within the national } \\
\text { target age range (age: } 23-65)\end{array}$ & 25,107 \\
\hline $\begin{array}{l}\text { Test coverage according to national } \\
\text { screening policy (3.5-yearly: age 23-65) }\end{array}$ & $67.7 \%$ \\
\hline
\end{tabular}

Source: Nordic Center of Excellence in Health-Related e-Sciences (NIASC) [11].

TABLE 3. Selected information on the Icelandic Breast Cancer Screening programme

\begin{tabular}{|l|l|}
\hline Description & Data \\
\hline Age range & $\begin{array}{l}\text { 40-69 years } \\
\text { (Women older than 69 } \\
\text { can attend at 2-year } \\
\text { intervals without invita- } \\
\text { tion but are not part of } \\
\text { the screening program) }\end{array}$ \\
\hline Screening interval & 2 years \\
\hline Participation rate & $\begin{array}{l}58 \%(2015-50-69 \\
\text { years)* }\end{array}$ \\
\hline $\begin{array}{l}\text { Invitation coverage (on } \\
\text { annual population) }\end{array}$ & N/A \\
\hline $\begin{array}{l}\text { Is written information on } \\
\text { benefits and harms of } \\
\text { screening provided? }\end{array}$ & N/A \\
\hline
\end{tabular}

Source: Sigurdsson K, Ólafsdóttir EJ [12].

refer the women for an open biopsy, wedge resection, or a mastectomy [12].

The ICS has for some time advocated for population based screening for colorectal cancer, and emphasises that it should start as soon as possible.

\section{ISRAEL CANCER ASSOCIATION: ADVOCACY, RESEARCH, AND CONTINUAL SUPPORT FOR BREAST CANCER SCREENING IMPLEMENTATION}

The Israel Cancer Association (ICA) was founded in 1952. Since its foundation, the ICA has had the mission to reduce morbidity and mortality rates of cancer by promoting research into the prevention and early detection of cancer, and to improve methods of treatment, rehabilitation, and quality of life for cancer patients and their families. The ICA's is supported by financial contributions from the public and receives no direct governmental funding. There are approximately 3,500 volunteers 
engaged with the ICA, who are active across the breadth of the 70 branches of the association.

Due to the high prevalence of breast cancer in Israel, ICA has worked tirelessly toward the reduction of breast cancer morbidity and mortality in Israel. The ICA has funded, for over two decades, the national mammography screening programme in Israel in collaboration with the Ministry of Health and healthcare funds. The programme itself was initiated by the ICA through the purchase of eight new mammography devices to replace existing, older devices [13].

From the outset, ICA has been at the forefront of advocacy, information, and training for health professionals and opinion leaders alike. In addition, the ICA has been the primary organisation informing women about mammography screening through dedicated media campaigns that clarify the importance of the programme. Written invitation for a free mammography screening is sent to all women over age 50 and up to age 75 in Israel, every other year. Women at higher risk of breast cancer are entitled to annual screening beginning at age 40 [14].

Even though the service is provided free of charge, achieving equal access to mammography screening had proved to be a challenge during the initial phases of implementation, particularly in geographic and socially remote areas, which are over-representative of women who are less aware of the screening programme.

One of the starkest inequities in the screening programme was the uptake of mammography screening by Jewish and Arab ethnicity women. In 2001, 49\% of Arab women participated in the mammography screening programme, compared $70 \%$ of Jewish women in the target age range. This variation was reflected subsequently in lower breast cancer mortality rates among Jewish women compared to Arab women in Israel [14].

To address this inequality the ICA invested in mobile mammography screening units, and ancillary resources dedicated to achieving equality in participation. In 2011, the disparity observed in mammography screening participation rates between Arab and Jewish women in Israel was eliminated, and breast cancer mortality amongst Arab women has since further declined. In addition, the coverage was increase amongst ultra-Orthodox women, and new immigrant women.

\section{CONCLUSION}

The contribution of cancer leagues is a key sustaining factor for the full and equitable implementation of organised cancer screening programmes, in compliance with the EU guidelines for quality assurance in cancer screening. As initiators, programme managers, and disseminators of information to professionals and the target groups for screening, cancer leagues perform essential and diverse roles supporting cancer screening programmes to achieve their objectives.
This short communication outlines, with three practical examples, the variety of ways in which cancer leagues are supporting the development, management, and quality improvement of organised cancer screening in the wider European region. In addition to the specific examples provided in this text, many other cancer leagues make significant contributions to cancer screening programmes across Europe.

ECL intends to harness this activity in the coming years by deepening the collaboration between cancer leagues on this issue, thereby acting on the ECL's strategic goal to "encourage access to cancer screening." To this end, actions will be proposed and implemented from 2018 to facilitate the cooperation between cancer leagues on salient topics for the effective implementation, monitoring and evaluation of organised cancer screening programmes.

\section{ACKNOWLEDGEMENT}

ECL has received funding under an operating grant (no: 747456) from the European Union's third health programme (2014-2020). The views expressed in this text do not necessarily reflect the official views of the EU institutions.

\section{DISCLOSURE}

Author reports no conflict of interest.

\section{References}

1. Council Recommendation of 2 December 2003 on cancer screening. Available from: http://eur-lex.europa.eu/LexUriServ/ LexUriServ.do?uri=J:L:2003:327:0034:0038:EN:PDF (accessed: 9 October 2017).

2. Ponti A, Anttila A, Ronco G, et al. Cancer Screening in the European Union Report on the implementation of the Council Recommendation on cancer screening. International Agency for Research on Cancer (IARC), Lyon 2017.

3. Armaroli P, Villain P, Suonio E, et al. European Code against Cancer, $4^{\text {th }}$ Edition: Cancer screening. Cancer Epidemiol 2015; 39 (Suppl 1): S139-152.

4. Schüz J, Espina C, Villain P, et al. European Code against Cancer, $4^{\text {th }}$ Edition: 12 ways to reduce your cancer risk. Cancer Epidemiol 2015; 39 (Suppl 1): S1-S10.

5. Association of European Cancer Leagues (ECL). ECL strategy 2014-2018. Available from: www.europeancancerleagues.org (accessed: 1 October 2017).

6. Zatoński W. Europejski kodeks walki z rakiem, wersja trzecia 2003 [European code against cancer and scientific justification: third version 2003]. Centrum Onkologii-Instytut im. Marii Skłodowskiej-Curie, Warsaw 2011.

7. Zatoński W, Pisarska-Krawczyk M, Wojtyła C, Janik-Koncewicz K. Patterns of cervical cancer mortality in young adult women in three countries of the European Union: Finland, Poland, and Latvia. J Health Inequal 2016; 2: 95-100. 
8. Wojtyła C, Słabuszewska-Jóźwiak A, Janik-Koncewicz K, Zatoński WA. New challenges for cervical cancer. J Health Inequal 2016; 2: 77-88.

9. European Commission. "Europe against Cancer" programme. 1995.

10. Bastos J, Rodrigues V, Paap E, et al. Breast cancer screening effectiveness in Portugal central Region. Eur J Cancer Prev 2017; 26: S204-S207.

11. Nordic Center of Excellence in Health-Related e-Sciences (NIASC). Cancer Screening Fact Sheet. Available from: http:// nordscreen.org/wp-content/uploads/2017/07/cervix-fact-sheeticeland-2017.pdf (accessed: 12 October 2017).

12. Sigurdsson K, Ólafsdóttir EJ. Population-based service mammography. the Icelandic experience. Breast Cancer: Targets and Therapy 2013; 5: 17-25.

13. Robinson E, Ziv M, Keinan-Boker L. Effectiveness of Organized National Breast Cancer Screening: The Israeli Experience. The ASCO Post. Available from: http://www.ascopost.com/issues/ august-10-2016/effectiveness-of-organized-national-breast-cancer-screening-the-israeli-experience/ (accessed: 7 October 2017).

14. Israel Cancer Association. Early Detection: Breast Cancer. Available from: http://en.cancer.org.il/ (accessed: 10 October 2017). 